\title{
Paired associate learning of function words ${ }^{1}$
}

\author{
R. KANUNGO \\ DALHOUSIE UNIVERSITY, HALIFAX
}

The implications of the unit and the grapnel interpretations for the associative learning of function words were tested. Results suggest that higher meaningfulness $(\underline{m})$ of function words do not facilitate their associative linkage, and that they behave like low $m$ nonsense words.

The implications of Glanzer's (1962) "unit" analysis and the grapnel or associative probability model (Underwood \& Schulz, 1960) for the paired associate (PA) learning of function words were tested in two experiments. Unlike the studies (Cofer, 1967; Glanzer, 1962) that compared function words with content words in PA learning, the present experiments compared function words with nonsense verbal items during the associative hook-up stage (Underwood \& Schulz, 1960) of PA learning.

According to Glanzer (1962) a function word alone is an incomplete unit like a bound morpheme. It derives its meaning (syntactic) and becomes a complete unit through its connection with other words. Without surrounding elements, a function word is like a nonsense form (devold of referential or syntactic meaning). In terms of unit analysis, therefore, the associative learning of function words in a PA setting will not differ from associative learning of nonsense verbal units. On the other hand, it may be argued that the function words evoke greater number of associations than nonsense verbal units because the former are used more often in varied word contexts in everyday language. In fact, Glanzer (1962) found larger variety of responses to function words than to content words. Thus, in terms of the grapnel model, the associative learning will be easier in the case of function words than in the case of nonsense verbal units.

\section{Materials}

The following 10 function words chosen from AA or A categories of Thorndike and Lorge (1944) count, included conjunctions, prepositions and adverbs ${ }^{2}$ : ABOUT, ENOUGH, FROM, HENCE, NEVER, QUITE, SUCH, TOWARD, UNTIL, WHILE. The 10 nonsense words were scrambled forms of function words: BAUTO, HEUGON, MORF, EHNEC, VEREN, TIQUE, CUSH, WADTOR, NILUT, and LEWIH. Thus for each function word there was a corresponding nonsense word having the same set of letters. Using the production method (Noble, 1952), the meaningfulness (m) of each of the 20 words was obtained from a group of $25 \mathrm{Ss}$. The $m$ values of the function words (mean $\underline{m}=4.14$ ) were significantly higher than the $\underline{m}$ values of the nonsense words (mean $\underline{m}=2.97, t=9.29, \mathrm{df}=9, \mathrm{p}<.001$ ).

\section{Experiment I}

The associative learning of function word pairs and nonsense word pairs were compared after equating response learning in both conditions. Four separate lists were prepared: $A-B(F W), A-B(N W), B-A(F W)$ and $B-A(N W)$. The $A-B(F W)$ list consisted of five pairs of function words, each pair having least inter-item association. The $A-B(N W)$ list consisted of five pairs of nonsense words corresponding to the pairs in the $A-B(F W)$ list. The $B-A(F W)$ and (NW) lists were prepared only by switching the stimulus and response positions of the words in the $A-B(F W)$ and (NW) lists respectively.

Subjects and Procedure. Forty-eight undergraduate students were randomly assigned to four groups of 12 each. Each group was assigned to learn a different list, and had to undergo two successive phases of learning the list: response learning and associative learning. During the response learning phase, the Ss were given 15 familiarization trials with each of the 10 words of the list to which they were assigned, in a random order. A single familiarization trial with a word involved exposing the word printed on a $3 \times 5$ in. index card for 10 sec and asking the Ss to pronounce it. After completion of the famliarization procedure, the Ss were asked to recall the words in order to ascertain the degree of response learning of the Ss.

During the associative learning phase that followed response learning, the Ss were asked to learn the PA list for 20 trials. The list was presented on a Stowe memory drum at a 2:2:4 sec rate using a standard anticipation procedure. Four different orders of the pairs in the list were used to minimize the effects of serial learning.

Results. Analysis of the free recall scores after the familiarization trials revealed that the response learning of the four lists did not differ significantly from each other $(F=2.78, \mathrm{df}=3 / 44, \mathrm{p}>.05)$. The mean recall scores for $A-B(F W), B-A(F W), A-B(N W)$ and $B-A(N W)$ lists were $8.67,7.75,7.75$ and 7.17 , respectively.

The associative learning scores of the four different lists were analyzed by first determining for each $\mathrm{S}$ the correct number of responses on each of the four blocks of five trials in each. The mean number of correct responses for the four lists on each of the four blocks are presented in Fig. 1. A 2 by 2 by 4 analysis of variance revealed that neither the function and nonsense word classification, nor the A-B,B-A order classification has any significant effect ( $F<1$ in each case). The mean number of correct responses during all the 20 trials for lists $A-B(F W), B-A(F W), A-B(N W)$ and $B-A(N W)$ were $58.17,50.00,53.67$, and 53.83 , respectively.

The results clearly reveal that, equated for response learning, the function word pairs are learned no better than nonsense word pairs. Explanation of these results in terms of the grapnel model seems inadequate, as the 


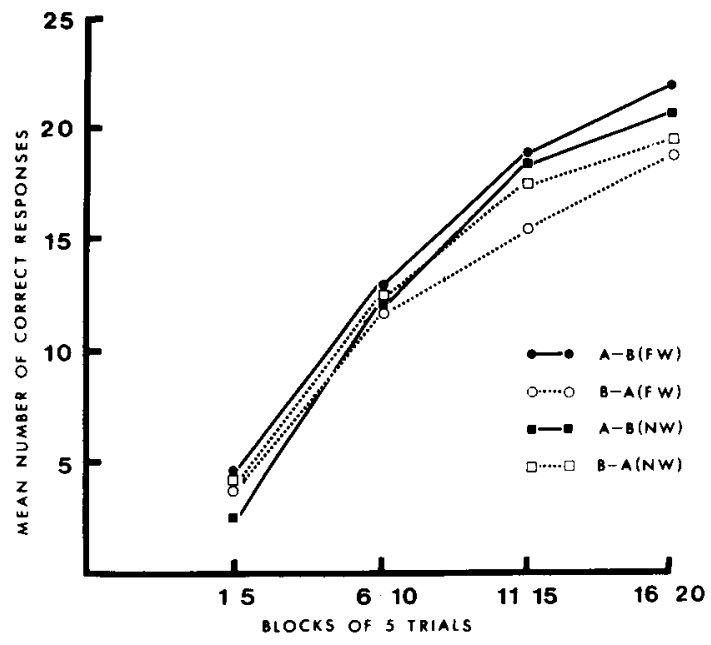

Fig. 1. Mean number of correct responses in Experiment 1.

model would have predicted superiority in the associative learning of function word pairs on the basis of their higher $\underline{m}$.

\section{Experiment 2}

In Experiment 2, the associative learning of the function and nonsense words were compared when these words were paired with two digit numbers and served either as stimuli or as responses in the PA lists. Thus, four PA lists, each containing five pairs, were prepared: D-FW, D-NW, FW-D and NW-D. The pairs in the D-FW list were: 50 NEVER, 24 ENOUGH, 91 HENCE, 73 $\mathrm{ABOUT}$, and $86 \mathrm{SUCH}$. The pairs in the D-NW list were: 50 VEREN, 24 HEUGON, 91 EHNEC, 73 BAUTO, and $86 \mathrm{CUSH}$. The items in the FW-D and the NW-D lists were the same as in the D-FW and D-NW lists, respectively, but the stimulus and response positions of the items were reversed.

Subjects and Procedure. Fifty-six Ss were randomly assigned to four groups of 14 Ss in each. Each group was assigned to learn a different list and had to undergo two, successive phases of learning. During the response learning phase, the Ss were given 15 familiarization trials with each of the five words of the list in a manner similar to that employed in Experiment 1. Following this, the Ss were asked to recall the words. During the associative learning phase, Ss were asked to learn the paired-associate list for 20 trials. The learning procedure was the same as in Experiment 1.

Results. Recall after familiarization trials indicated that each $\mathrm{S}$ could recall all the five words of the list to which he was assigned. Thus, while entering the associative learning phase, all the nonsense or the function words of the list were available to the Ss.

For associative learning, the mean number of correct responses for each of the four lists were calculated. These are presented in Fig. 2 for four blocks of five

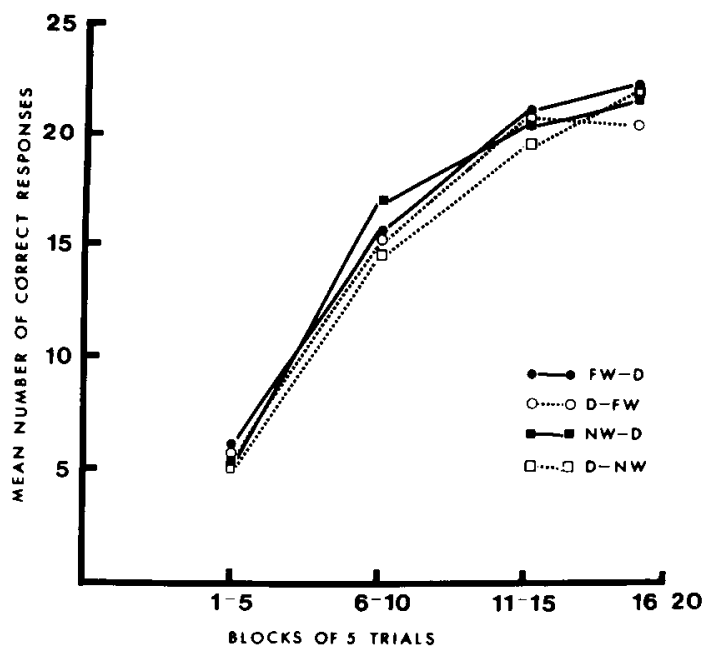

Fig. 2. Mean number of correct responses in Experiment 2.

trials in each. A 2 by 2 by 4 analysis of variance revealed that the word effects (function and nonsense words) and the position effects (stimulus and response positions) are non-significant ( $F<1$ in each case). The mean number of correct responses during all the 20 trials for lists FW-D, NW-D, D-FW and D-NW were 68.93,68.57, 64.78 and 63.71 , respectively.

These results again are similar to those of Experiment 1 in demonstrating that associative learning of function and nonsense words do not differ significantly. Associating a function word with another item is like associating a nonsense word with that item. This suggests that the $\underline{m}$ of function words that have no referential meaning may not facilitate their associative linkage. The results, however, are consistent with Glanzer's (1962) notion that function words without the surrounding elements are devoid of any meaning and, hence, equivalent to nonsense words.

\section{References}

COFER, C. N. Learning of content and function words in nonsense syllable frames: A repetition and extension of Glanzer's experiment. $J$. verbal Learn. verbal Behav., 1967, 6, 198-202.

GLANZER, M. Grammatical category: A rote Learning and word association analysis. J. verbal Learn verbal Behav., 1962, 1, 31-41.

KLEIN, S., \& SIMMONS, R. F. Automated analysis and coding of English grammar for information processing systems. Systems Development Corp. Rep. SP-490, Santa Monica, Calif., 1961.

NOBLE, C. E. An analysis of meaning. Psychol Rev., 1952, 59, 421-430.

THORNDIKE, E. L., \& LORGE, I. The teacher's word book of 30,000 words. New York: Teacher's College, Columbia Univ., 1944.

UNDERWOOD, B. J., \& SCHULTZ, R. W. Meaningfulness and verbal learning. Chicago: Lippincott, 1960.

Notes

1. The study was supported by Grant No. X-12-179 from National Research Council, Canada.

2. Adverbs that do not end in -ly are considered as function words by Klein and Simmons (1961). Besides, the adverbs were chosen as function words to introduce maximum difference in $\mathrm{m}$ between the function and the nonsense words. 